\title{
Hidatidosis gigante de múltiple localización
}

\section{Giant multiple site hydatidosis}

\author{
Jesús Neyra-León, ${ }^{*,+}$ Nicolás De la Cruz-Chacaliaza, ${ }^{\ddagger}$ Juan Carlos Díaz-Monge ${ }^{\S}$ \\ ${ }^{*}$ Facultad de Medicina, Universidad Privada San Juan Bautista. ${ }^{\ddagger}$ Servicio de Pediatría, \\ $\S$ Servicio de Medicina Interna, Hospital Regional de Ica. Ica, Perú.
}

\section{RESUMEN}

Presentamos las imágenes tomográficas de una paciente de ocho años con quistes gigantes en hígado y pulmón secundarios por equinococosis.

Palabras clave: Equinococosis, equinococosis pulmonar, equinococosis hepática, niños.

Escolar femenino de ocho años, proveniente de la Sierra de Perú, con antecedente de nacimiento domiciliario por vía vaginal y quien nunca había sido atendida en un centro de salud. Acude por cuadro de tres semanas de tos persistente, productiva, blanquecina, y de sabor salado (sic), la cual se asociaba a dolor abdominal, localizado en hipocondrio derecho. $\mathrm{Al}$ examen físico, el murmullo estaba disminuido en tercio superior de hemitórax derecho (Figuras 1 y 2); el abdomen se observó distendido, con hepatomegalia palpable de $7 \mathrm{~cm}$ por debajo del reborde costal.

Se le realiza una tomografía de cuerpo entero. En abdomen en la vista coronal se observaron dos imágenes quísticas en hígado con edema adyacente, una ubicada entre segmento V-VI circunferencial, que midió $70 \times 60 \times 105 \mathrm{~mm}$; la segunda, se localizaba en el lóbulo hepático izquierdo con membranas desprendidas, con dimensiones de $110 \times 56 \times 51 \mathrm{~mm}$ (Figuras 3 y 4 ).

+ Correspondencia: JANL, jesus.24.47.1996@gmail.com Conflicto de intereses: Los autores declaran que no tienen. Citar como: Neyra-León J, De la Cruz-Chacaliaza N, Díaz-Monge JC. Hidatidosis gigante de múltiple localización. Rev Mex Pediatr. 2020; 87(4): 150-152. https://dx.doi.org/10.35366/95826

\section{ABSTRACT}

We present tomographic images of an eight-year-old female patient with giant cysts in the liver and secondary lung due to echinococcosis.

Keywords: Echinococcosis, pulmonary echinococcosis, hepatic echinococcosis, children.

Por otra parte, en el tórax también se identificó una imagen quística en segmento posterior del lóbulo superior derecho de $30 \mathrm{~mm}$ de diámetro, con membranas desprendidas hiperdensas en su interior.

Se realiza prueba de arco quinto (DD5), la cual sale positiva, por lo que se llega al diagnóstico de

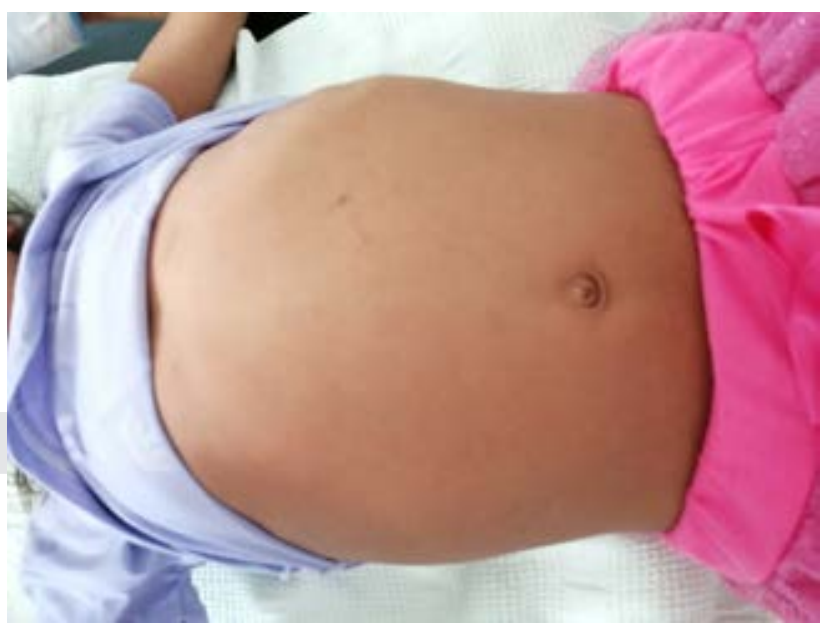

Figura 1: En posición decúbito dorsal se aprecia abdomen globuloso distendido a predominio derecho. 


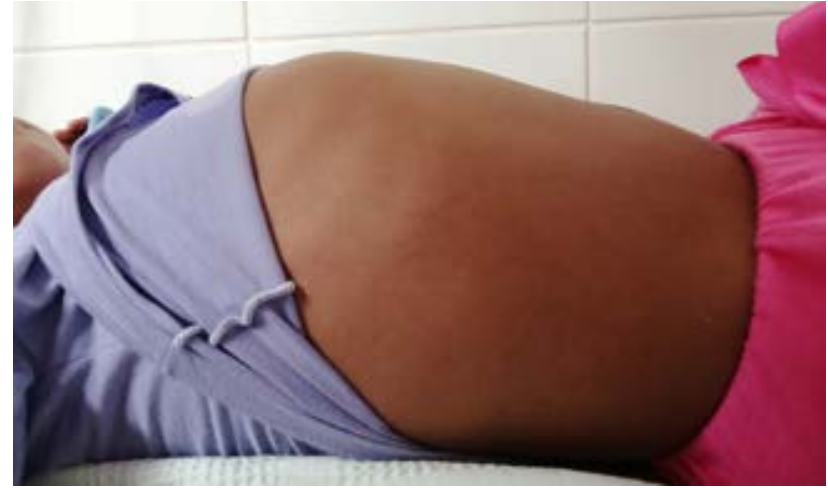

Figura 2: En la vista lateral del abdomen de la paciente se aprecia abdomen globuloso distendido a predominio derecho.

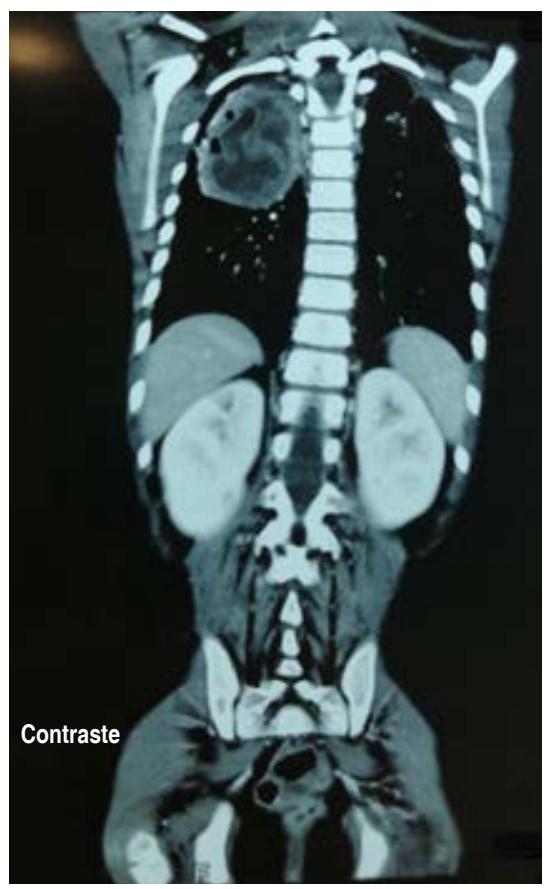

Figura 3: Vista coronal de la tomografía de tórax con contraste. Se observa gran imagen quística en lóbulo superior derecho con membranas desprendidas hiperdensas.

equinococosis múltiple. Se refiere a un hospital de mayor complejidad para exéresis de quiste; posterior a lo cual queda en tratamiento con albendazol en dosis de $10 \mathrm{mg} / \mathrm{kg}$ de peso/día, en dos tomas diarias luego del almuerzo y la cena, por tres ciclos de 30 días cada uno sin interrupciones. En la actualidad, la paciente se encuentra a la espera de una segunda intervención quirúrgica y con una evolución favorable.
La equinococosis continúa siendo un problema de salud pública en Latinoamérica, debido a sus altas tasas de incidencia. Esta enfermedad es una zoonosis causada por el estado larval del cestodo Echinococcus del género Granulosus. Las dos formas más importantes de esta enfermedad son la equinococosis quística (hidatidosis) y la equinococosis alveolar. La localización más frecuente de los quistes son en hígado (65\%) y pulmón (30\%). ${ }^{1}$
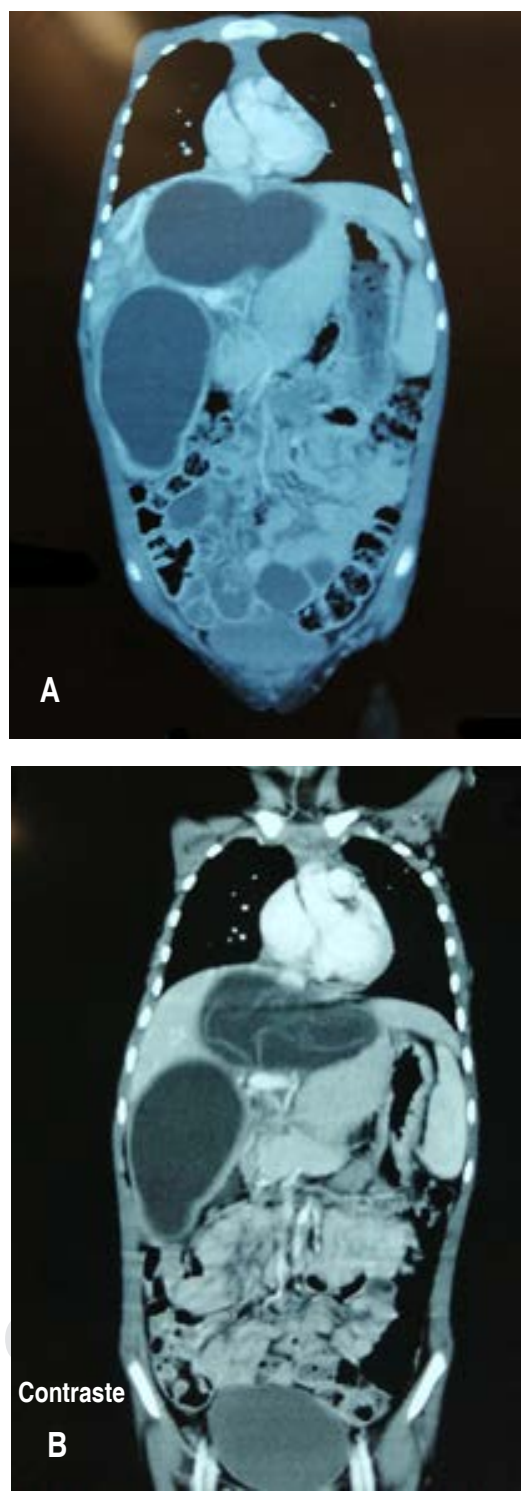

Figura 4: A y B) Vista coronal de la tomografía de abdomen con contraste y sin contraste. Se observan dos imágenes quísticas gigantes en lóbulo hepático derecho e izquierdo. 
Uno de los factores de riesgo que más se asocian con esta entidad es la crianza de ovinos y perros, debido al ciclo de vida del parásito. El diagnóstico en estadios avanzados de la enfermedad, generalmente es en personas con bajo nivel educativo y por las limitaciones en la atención primaria en países subdesarrollados. ${ }^{2}$ El tratamiento dependerá del tamaño y características de los quistes, por lo que los estudios de imagen son necesarios para determinar el plan terapéutico. $^{3}$

\section{REFERENCIAS}

1. Huamán I, Marocho L, López T, Gavidia C. Frequency of hydatidosis of children and adolescents hospitalized in the National Child Health Institute (Period 1996-2005). Rev Invest Vet Perú. 2010; 21(1): 54-60.

2. Petropoulos A, Chatzoulis G. Echinococcus granulosus in childhood: A retrospective study of 187 cases and newer data. Clin Pediatr (Phila). 2019; 58(8): 864-888. doi: 10.1177/0009922819847032.

3. Shangareyeva R, Mirasov A, Glazyrina V, Timerbaeva E. Combined echinococcosis management in children. Khirurgiia (Mosk). 2017; (1): 48-53. doi:10.17116/hirurgia2017148-53. 